\title{
Effects of cholinesterase inhibitors appear greater in patients on established antihypertensive therapy
}

\author{
Luca Rozzini $^{1,2} *$, Barbara Vicini Chilovi ${ }^{1,2}$, Giuseppe Bellelli ${ }^{1,3}$, Erik Bertoletti ${ }^{1}$, \\ Marco Trabucchi ${ }^{2}$ and Alessandro Padovani ${ }^{2}$ \\ ${ }^{1}$ Department of Neurology and University of Brescia, Italy \\ ${ }^{2}$ Geriatric Research Group, Brescia, Italy \\ ${ }^{3}$ Ancelle della Carità Hospital, Cremona, Italy
}

\section{SUMMARY}

Introduction There is increasing evidence that hypertension may contribute to development of dementia. Studies show that blood pressure lowering therapy might protect against cognitive deterioration and that antihypertensive treatment reduce the incidence of dementia.

Aim We hypothesize that administration of cholinesterase inhibitors (AChEis) to patients with Alzheimer's Disease (AD) receiving antihypertensive medications therapy would result in clinical benefits for a period of 40 weeks in routine clinical practice.

Methods and materials Patients with possible or probable AD were enrolled from 16 Alzheimer evaluation units (UVA) of Brescia and Cremona (Northern Italy). Patients treated with donepezil, rivastigmine and galantamine for 40 weeks independently of dosages were selected. Patients were evaluated at baseline (T0), 4 weeks (T1), 16 weeks (T2) and 40 weeks (T3).

Results 416 patients completed the study at 40 weeks; of these 255 were 'non users' while 161 utilized antihypertensive drugs ('users'). The mean change in MMSE score from baseline to week 40 demonstrate that antihypertensive-treated patients improved by 0.7 points while patients receiving only AChEis remain stables. Analyzing separately patients $(n=183)$ that ameliorate (responders) on cognition at T3 $(\geq 1$ point MMSE score increase) a significant differences in favor of 'users' antihypertensive drugs over 'non users' on cognition at weeks 16 and 40 has been demonstrated. In particular, at T2 the mean change of MMSE from baseline in 'users' was $3.2 \pm 2.6 v s$ 'non users' $2.2 \pm 2.3(p=0.016)$ and at T3 was $3.5 \pm 2.5 \mathrm{vs}$ 'non users' 2.0.2.7 $\pm 1.6(p=0.018)$. Antihypertensive drugs were independently associated with cognitive improvement in responder patients treated with AChEis (95\% CI: $0.41-1.79 ; p=0.002)$.

Conclusion Antihypertensive medications in AD patients treated with AChEis are associated with an independent improvement on cognition after 40 weeks of treatment. Copyright (C) 2005 John Wiley \& Sons, Ltd.

KEY WORDS - cholinesterase inhibitors; antihypertensive drugs; Alzheimer's disease; cognition; real world study; functional status

\section{INTRODUCTION}

There is increasing evidence that hypertension may contribute to the development of cognitive impairment and dementia (Skoog et al., 1996; Birkenhager et al., 2004; Staessen et al., 2004). It follows that blood pressure lowering therapy might protect against cognitive deterioration. The Syst-Eur trial (Forette

*Correspondence to: L. Rozzini, Department of Neurology, University of Brescia, Spedali Civili, Piazzale Spedali Civili, 1, 25100 Brescia, Italy. E-mail: 1rozzini@iol.it et al., 2002) observed that antihypertensive treatment, compared with placebo, reduced the incidence of dementia by $50 \%$ from 7.7 to 3.8 cases by 1000 patient-years and the Rotterdam study (in't Veld et al., 2001) demonstrated that dementia may be prevented by antihypertensive treatment.

However, to our knowledge the joint effects of antihypertensive medications and AChEis in demented patients has never been studied.

On the base of our data, we hypothesize that administration of AChEis to patients with mild to moderate $\mathrm{AD}$ receiving antihypertensive medications would 
result in clinical benefit for a period of 40 weeks in routine clinical practice.

\section{METHODS}

This 40-week, multicenter study was conducted in 16 Alzheimer Evaluation Units of the Italian 'Cronos project'. This project was enacted by the Italian Ministry of Health (September, 2000) to address the issue of Alzheimer's disease treatment in Italy. Global cognitive function was assessed using the Mini Mental State Examination (MMSE; Folstein et al., 1975), while functional capacity was assessed with the Basic Activity of Daily Living (BADL; Katz et al., 1970) and the Instrumental Activity of Daily Living Scale (IADL; Lawton and Brody, 1969). Patients considered in our study had mild to moderate AD (MMSE score from $\geq 10$ to $\leq 26$ ); we excluded from the analysis patients that stopped the treatment before the end of the planned observation period. At baseline, all participants were asked whether or not they had a history of hypertension and the specific treatment. We assumed that drugs with antihypertensive proprieties were used chronically. All patients were considered at the baseline (T0) (starting with donepezil, rivastigmine, or galantamine) and were re-evaluated after 4 weeks (T1), 16 weeks (T2) and 40 weeks (T3).

\section{Statistical methods}

Statistical analysis was performed with the Statistical Package for the Social Sciences, release 11.5.1. Descriptive statistics are presented as mean values and standard deviation or percentages, according to the nature of the variable. $T$-test was used to compare continuous variables and chi-square test for dichoto- mous ones. All tests were two-tailed at a probability level 0.05 . The significance of change from baseline to 4, 16 and 40 weeks for MMSE was evaluated through the General Linear Model (GLM). Linear regression model was used to identify whether variables were independently associated with cognitive improvement $(\geq 1$ point MMSE score increase indicate improvement) in patients treated with $\mathrm{AChEis}$ at $\mathrm{T} 3$.

\section{RESULTS}

Four hundred and sixteen patients with mild to moderate Alzheimer's disease were included in the present study and completed the observation at T3. Patients were divided in 'users' $(n=161)$ and 'non users' $(n=255)$ antihypertensive drugs (Table 1$)$. The number of disease $(p=0.000)$ was significantly higher in 'users', female gender was more represented in 'users' ( $p=0.05)$, while age, MMSE, level of education and the activities of daily living (BADL and IADL) were comparable between groups. At baseline, of the 161 demented patients taking antihypertensive medication, 48\% reported use of Angiotensin Converting Enzyme (ACE) inhibitors, 16\% of diuretics, $15 \%$ of calcium antagonist, $12 \%$ of beta-blockers; $9 \%$ used two or more drugs or other antihypertensives (alpha-blockers or angiotensin II receptor antagonists). Patients received at baseline donepezil $(n=282 ; 67.8 \%)$, rivastigmine $(n=100 ; 24.0 \%)$ and galantamine $(n=34 ; 8.2 \%)$ as per the clinician's judgment at different dosages (Donepezil 5-10 mg/ daily; Rivastigmine $1.5-3 \mathrm{mg} / \mathrm{b}$.i.d. or higher; Galantamine $4-8 \mathrm{mg} /$ b.i.d. or higher). In all patients we observed a mean improvement from baseline of the MMSE score at weeks 40 (MMSE mean change $0.2 \pm 3.2 ; p=0.08)$.

Table 1. General characteristics of participants $(n=416)$ divided in 'non users' and 'users' of antihypertensive drugs

\begin{tabular}{|c|c|c|c|c|c|c|c|}
\hline & \multicolumn{3}{|c|}{$\begin{array}{l}\text { Non users } \\
(n=255)\end{array}$} & \multicolumn{3}{|c|}{$\begin{array}{l}\text { Users of antihypertensive drugs } \\
\qquad(n=161)\end{array}$} & \multirow[b]{2}{*}{$p$. } \\
\hline & Mean & $\mathrm{SD}$ & $\%$ & Mean & SD & $\%$ & \\
\hline Sex, female & & & 70.6 & & & 78.3 & 0.05 \\
\hline Age, years & 76.8 & 6.6 & & 78.1 & 6.0 & & 0.05 \\
\hline Education, years & 5.6 & 2.8 & & 5.2 & 2.4 & & NS \\
\hline Duration of the disease, months & 25.9 & 12.9 & & 25.9 & 15.7 & & NS \\
\hline MMSE & 19.4 & 3.7 & & 19.3 & 3.8 & & NS \\
\hline IADL (functions maintained) & 3.7 & 2.7 & & 3.8 & 2.4 & & NS \\
\hline BADL (functions maintained) & 4.0 & 2.2 & & 3.9 & 2.3 & & NS \\
\hline Number of diseases* & 0.3 & 0.6 & & 1.5 & 0.7 & & 0.000 \\
\hline
\end{tabular}

$\mathrm{NS}=$ not significant; MMSE $=$ Mini Mental State Examination; IADL $=$ Instrumental Activities of Daily Living; BADL $=$ Basic Activities of Daily Living; *excluding dementia. 
Significant differences in favor of antihypertensive 'users' over 'non users' were observed for the mean change from baseline on the MMSE at week 16 (Mean change MMSE $1.1 \pm 2.8$ vs $0.4 \pm 2.9 ; p=$ $0.02)$. Furthermore, at T3 observed a significant functional decline was not observed, characterized by the loss of ability to perform activities of daily living (BADL and IADL), in patient 'users' and 'non users' antihypertensive medications, responders and non responders to AChEis.

Analyzing separately patients $(n=183)$ that ameliorate (responders) on cognition at $\mathrm{T} 3$ ( $\geq 1$ point total MMSE score increase, indicating responders) significant differences in favor of 'users' over 'non users' on cognition at weeks 16 and 40 have been found (Figure 1). In particular, at T2 the mean change of MMSE from baseline in 'users' was $3.2 \pm 2.6$ vs 'non users' $2.2 \pm 2.3(p=0.016)$ and at T3 was $3.5 \pm 2.5 v s$ 'non users' $2.7 \pm 1.6(p=0.018)$.

Also, in patients that worsen $(0$ or 1 point total MMSE score decrease, indicating non responders) we did not observe significant differences on MMSE change at T2 between 'user' and 'non user' antihypertensive drugs $(0.52 \pm 2.04$ vs $0.87 \pm 2.6 ; p=\mathrm{NS})$, while at $\mathrm{T} 3$ it has been found a significant worsening in patients who did not assume antihypertensive medications (mean change of MMSE from baseline 'users' $-1.6 \pm 1.6$ vs 'non users' $-2.3 \pm 2.3$; $p=0.036$ ) was found.

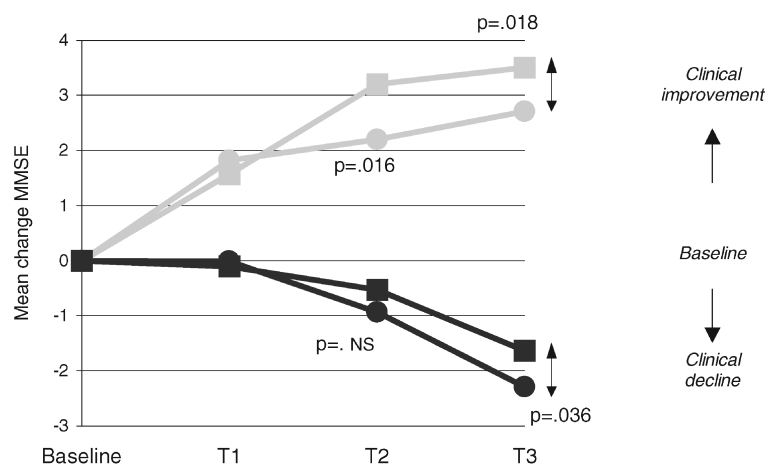

Users of antihypertensive drugs

Non users antihypertensive drugs

Clear line indicating responders to AChEis Dark line indicating non responders to AChEis

Figure 1. Mean changes of MMSE from baseline and after 40 weeks of treatment with AChEis, for AD patients that improve $(n=183)$ (clear line, 1 point or more MMSE score increase, indicating responders) and in patients that worsen $(n=233)$ (dark line) indicating non responders
To determine the variables independently associated with cognitive improvement after 40 weeks of treatment with AChEis, the association between cognitive improvement and potential determinants (age, sex, education, MMSE at baseline and higher dose of AChEis at T2) was calculated with a linear regression model. In responder patients the utilization of antihypertensive drugs [ $(95 \%$ Confidence Intervals (CI): $0.41-1.79 ; p=0.002)]$ was independently associated with cognitive improvement. In non responder patients the same trend although not statistically significant (95\% CI: $-0.32-0.93 ; p=0.33$ ) was found.

\section{DISCUSSION}

To our knowledge, this is the first published study examining the benefits of the joint effect of AChEis and antihypertensive medications on a real world representative population of mild to moderate Alzheimer's disease patients. The effect exerted by AChEis use in this study is comparable to previously reported randomized and open-label placebo controlled trials. In fact, the majority of these trials, using either donepezil, rivastigmine or galantamine, demonstrate an initial improvement in cognitive performances during the first 12 weeks, returning to close to or baseline levels at the end of the treatment period (Farlow et al., 2000; Raskind et al., 2000; Rogers et al., 2000; Tariot et al., 2001). These studies show that the mean effect of the drug over placebo represents an improvement in cognition roughly equivalent to stemming 6-12 months of natural decline in untreated patients (O'Brien and Ballard, 2001). Our findings confirm a similar pattern, even if the study environment is different from the clinical trials. In fact, cognitive performances changed by 0.2 MMSE points from baseline to 40 weeks, a rate which was very similar to previous studies that used MMSE score as an outcome measure (Rogers et al., 1998; Winblad et al., 2001).

In our study we found strong joint effect of antihypertensives and AChEis. To date, literature analysis does not clarify whether the cognitive improvement due to these treatments is a synergic or an independent effect. Recent findings indicate that AChEis, above all rivastigmine, are effective particularly in patients with vascular risk factors (Kumar et al., 2000), in line with other data (Erkinjunti et al., 2003) showing that additional apparent benefit in Alzheimer's disease patients treated with AChEis may be linked to drug effect on cerebrovascular factors. Experimental data on antihypertensive medications, particularly ACE inhibitors and calcium channel-blockers, hypothesized a 
function on cognition of these drugs. In fact, studies (Hirawa et al., 1999; Savaskan et al., 2001; Ohrui et al., 2004) have reported elevated levels of ACE in the hippocampus, parahippocampal gyrus, frontal cortex, and caudate nucleus of $\mathrm{AD}$ patients. The increased ACE activity may be directly responsible for cognitive impairment in $\mathrm{AD}$ because the enhanced formation of angiotensin II would result in an increased inhibitory effect on acethylcholine release (Barnes et al., 1991). On the same line Sudilovsky et al. (1987) suggest that ACE may have a role in the modulation of cognitive memory processes in rat and in humans. They found that angiotensin II impair performance on various learning and memory paradigms in animals (Melo et al., 1975; Morgan and Routtenberg, 1977) and that the effect is prevented by captopril administration.

Recently, Parihar and Hemnani (2004) underlined the role of calcium channel blockers as a possible therapeutic approach to $\mathrm{AD}$. This hypothesis is supported by Pierrot et al. (2004) demonstrating that calcium channel blockers, through reduction of cytosolic calcium concentration, inhibit the production of intraneuronal A- $\beta-1-42$ responsible for neuronal death. Moreover, in an experimental model Popovic et al. (1997) compared the effect of a cholinesterase inhibitor (physostigmine) and a calcium antagonist (verapamil) on two-way active avoidance learning (acquisition and performance) in nucleus basalis magnocellularis-lesioned rats. They concluded that verapamil significantly improved both types of learning, even when associated with physostigmine.

Our study has limitations. Firstly, we do not have informations on temporal relation between the use of antihypertensive drugs and cognitive decline and we not provide data on potential differential cognitive effects associated with various antihypertensive agents.

\section{ACKNOWLEDGMENTS}

The following researchers are members of the Brescia-Cremona study group:

1. Alessandro Padovani, Barbara Vicini Chilovi, Elisabetta Cottini, Erik Bertoletti, Elena Bazzoli, Department of Neurology, University of Brescia; Brescia;

2. Angelo Bianchetti, Giovanna Cipriani, 'S. Anna' Hospital, Brescia;

3. Renzo Rozzini, Stefano Boffelli, 'Poliambulanza' Hospital, Brescia;

4. Simone Franzoni, Laura Gatti, CMR Richiedei, Palazzolo s/O Hospital, Brescia;
5. Marinella Turla, Department of Neurology, 'Valle Camonica' Hospital, Esine, Brescia;

6. Alberto Ranzenigo, 'S. Orsola Fatebenefratelli' Hospital, Brescia;

7. Giorgio Dalla Volta and Patrizia Civelli 'Città di Brescia' Hospital, Brescia;

8. Roberto Leonard, CMR Richiedei, Gussago, Brescia;

9. Franceso Maria Saviotti, 'Department of Psichiatry', Leno, Brescia;

10. Cesare Bargnani, Department of Neurology, 'Clinica San Rocco', Ome, Brescia;

11. Francesco Chia, Departement of Neurology, 'A. O. M. Mellini', Chiari, Brescia;

12. Giuseppe Bellelli, Elena Lucchi, 'Ancelle della Carità' Hospital, Cremona;

13. Attilio Calza, Sara Mondini, 'Figlie di S. Camillo' Hospital, Cremona;

14. Daniele Villani, M. Chiara Ubezio 'Istituto Ospedaliero di Sospiro', Sospiro;

15. Stefano Avanzi, Emanuela Galante IRCCS Fondazione Maugeri, Castelgoffredo;

16. Tommaso Riccardi, Luciana Groppelli, Department of Neurology, Provincial Hospital, Crema.

\section{REFERENCES}

Barnes NM, Cheng CHK, Costal B, et al. 1991. Angiotensin converting enzime density is increased in temporal cortex from patients with Alzheimer's disease. Eur J Pharmacol 200: 289292.

Birkenhager WH, Forette F, Staessen JA. 2004. Dementia and antihypertensive treatment. Curr Opin Nephrol Hypertens 13(2): $225-230$.

Erkinjunti T, Skoog I, Lane R, Andrews C. 2003. Potential longterm effects of rivastigmine on disease progression may be linked to drug effects on vascular changes in Alzheimer brains. 57(9): 756-760.

Farlow M, Anand R, Messina J Jr. 2000. A 52-week study of the efficacy of rivastigmine in patients with mild to moderately severe Alzheimer's disease. Eur Neurol 44: 236-241.

Folstein MF, Folstein SE, McHugh PR. 1975. 'Mini-mental state'. A practical method for grading the cognitive state of patients for the clinician. J Psychiatr Res 12: 189-198.

Forette F, Seuz M, Staessen JA, et al. 2002. The prevention of dementia with antihypertensive treatment. Arch Intern Med 162: 2046-2052.

Hirawa N, Uehara Y, Kawabata Y, et al. 1999. Long-term inhibition of renin-angiotensin system sustains memory function in aged Dahl rats. Hypertension 34(3): 496-502.

in't Veld BA, Ruitenberg A, Hofman A. 2001. Antihypertensive drugs and incidence of dementia: the Rotterdam Study. Neurobiol Aging 22(3): 407-412.

Katz S, Downs TD, Cash HR, Grotz RC. 1970. Progress in development of the index of ADL. Gerontologist 10: 20-30.

Kumar V, Anand R, Messina J, Hartman R, Veach J. 2000. An efficacy and safety analysis of Exelon in Alzheimer's disease patients with concurrent vascular risk factors. Eur J Neurol 7(2): 159-169. 
Lawton MP, Brody EM. 1969. Assessment of older people: selfmaintaining and instrumental activities of daily living. Gerontologist 9: 179-186.

Melo JC, Graeff FG. 1975. Effect of intracerebroventricular bradykinin and related peptides on rabbit operant behavior. J Pharmacol Exp Ther 193(1): 1-10.

Morgan JM, Routtenberg A. 1977. Angiotensin injected into the neostriatum after learning disrupts retention performance. Science 1;196(4285): 87-89.

O’Brien JT, Ballard CG. 2001. Drugs for Alzheimer's disease. BMJ 323: $123-124$

Ohrui T, Matsui T, Yamaya M, et al. 2004. Angiotensin-converting enzyme inhibitors and incidence of Alzheimer's disease in Japan. J Am Geriatr Soc 52(4): 649-650.

Parihar MS, Hemnani T. 2004. Alzheimer's disease pathogenesis and therapeutic interventions. J Clin Neurosci 11(5): 456-467.

Pierrot N, Ghisdal P, Caumont AS, Octave JN. 2004. Intraneuronal amyloid-beta1-42 production triggered by sustained increase of cytosolic calcium concentration induces neuronal death. J Neurochem 88(5): 1140-1150.

Popovic M, Popovic N, Jovanova-Nesic K, et al. 1997. Effect of physostigmine and verapamil on active avoidance in an experimental model of Alzheimer's disease. Int J Neurosci 90(1-2): 87-97.

Raskind MA, Peskind ER, Wessel T. 2000. Galantamine in AD: A 6-month randomized, placebo-controlled trial with a 6-month extension. The Galantamine USA-1 Study Group. Neurology 54: 2261-2268.
Rogers SL, Farlow MR, Doody RS, et al. 1998. A 24-week, doubleblind, placebo-controlled trial of denepezil in patients with Alzheimer's disease. Donepezil Study Group. Neurology 50: 136-145.

Rogers SL, Doody RS, Pratt RD, et al. 2000. Long-term efficacy and safety of donepezil in the treatment of Alzheimer's disease: final analysis of a US multicentre open-label study. Eur Neuropsyhcopharmacol 10: 195-203.

Savaskan E, Hock C, Olivieri G, et al. 2001. Cortical alterations of angiotensin converting enzyme, angiotensin II and AT1 receptor in Alzheimer's dementia. Neurobiol Aging 22(4): 541-546.

Skoog I, Lernfelt B, Landahl S, et al. 1996. 15-year longitudinal study of blood pressure and dementia. Lancet 347: 1141-1145.

Staessen JA, Thijisq L, Fagard R, et al. 2004. Effects of immediate versus delayed antihypertensive therapy on outcome in the Systolic Hypertension in Europe Trial. J Hypertens 22(4): 847-857.

Statistical Package for the Social Sciences for Windows, release 11.5.1 (Italian version). SPSS Inc.: Chicago (IL); 2002.

Sudilovsky A, Turnbull B, Croog SH, Crook T. 1987. Angiotensin converting enzyme and memory: preclinical and clinical data. Int J Neurol 88: 21-22: 145.

Tariot PN, Cummings JL, Katz IR, et al. 2001. A randomized, double-blind, placebo-controlled study of the efficacy and safety of donepezil in patients with Alzheimer's disease in the nursing home setting. J Am Geriatr Soc 49: 1590-1599.

Winblad B, Engedal K, Soininen H, et al. 2001. Donepezil Nordic Study Group: a 1-year, randomized, placebo-controlled study of donepezil in patients with mild to moderate AD. Neurology 57: 489-495. 